CASE RePorT

\title{
Orthodontic Microimplants and Its Applications
}

\author{
Rajesh Patil ${ }^{1}$, Girish Karandikar ${ }^{2}$, Manish Sonawane ${ }^{3}$
}

\begin{abstract}
Microimplants usage has revolutionized the clinical orthodontic practice over last few years. Their diverse clinical applications and ease of usage has simplified orthodontic cases requiring maximum anchorage. Their application in minor tooth movements for facilitation of prosthodontic restoration in overerupted or drifted teeth without usage of orthodontic brackets will soon find favour with other dental specialties.
\end{abstract}

Key Words: Microimplants, Anchorage, Intrusion, Retraction, Supraeruption

\section{Introduction}

Microimplants also known sometimes as Mini screws, Mini implants and wrongly as TAD`S (Temporary anchorage devices) are currently being branded as Holy Grail of orthodontics.

Since specialty of orthodontics emerged, orthodontists have been quite obsessed with anchorage planning. Anchorage control is one of the most important aspects of orthodontic treatment. There are times when absolute or maximum anchorage is needed. Various appliances for anchorage purpose have been designed which were either too cumbersome or depended on unreliable patient compliance.

A Microimplant is a titanium-alloy miniscrew, ranging from 6 to $12 \mathrm{~mm}$ in length and 1.2 to $2 \mathrm{~mm}$ in diameter, that is inserted into bone temporarily to enhance orthodontic anchorage. Procedure is minimally invasive and often completed using only topical anesthetic. They can be inserted directly through the gingival tissue into bone with a hand driver.

Microimplants act as stationary anchorage from which forces can be delivered without having undesirable side effects.

\footnotetext{
1 Reader

2 Professor and Head

3 Lecturer

Dept. of Orthodontics

MGM Dental College, Navi Mumbai

Address for Correspondence:

Dr. Rajesh Patil

Reader, Dept. of Orthodontics

MGM Dental College

Kamothe, Navi Mumbai

Mob: 9819008120

Email: rajeshpatil1977@gmail.com
}

\section{History of Skeletal Anchorage}

Gainsforth and Higley in $1945^{1}$ used vitallium screws in the dog ramus for purpose of anchorage. This experiment led to failure.

Linkow (1969) ${ }^{2}$ had some clinical success using mandibular blade-vent implants for retraction of maxillary incisors.

Roberts (1984) ${ }^{3}$ investigated and found that endosseous implants had future potential to be used as source of firm anchorage.

Kanomi (1997) ${ }^{4}$ reported that $1.2 \mathrm{~mm}$ diameter titanium mini implants provide sufficient anchorage for intruding the teeth.

Numerous other attempts were taken to gain use of microimplants for purpose of absolute anchorage over years.

Availability of titanium alloys, latest designs and interaction with fellow dental implantologists have allowed orthodontists currently to reliably place and use implants for cases which were considered very difficult or impossible to treat.

\section{Clinical Applications of Microimplants}

Currently Microimplants are mostly used in cases of high anchorage requirement, loss of anchor teeth, open bite cases, intrusion of teeth, uprighting of drifted molars and in periodontally compromised cases. (Fig. 1,2)

\section{Implant Design and Size}

The contemporary microimplant is made up of titanium alloy. It is self drilling or self tapping. (Fig. 3) Self drilling design is preferred due to ease of use and less chances of failure.

The contemporary microimplant diameter ranges from 1.2 to $1.8 \mathrm{~mm}$ and is $5-11 \mathrm{~mm}$ in length. 


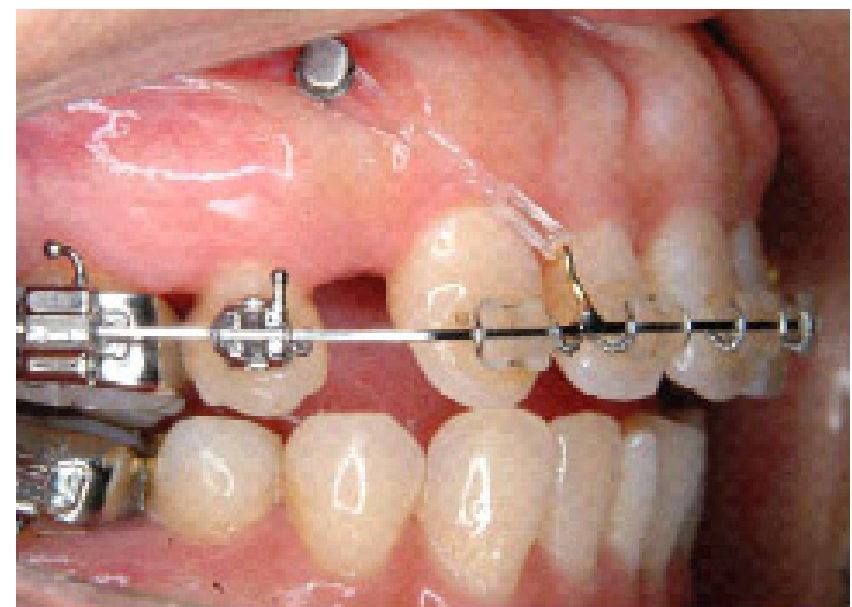

Fig. 1 - Microimplant used for retraction of anterior teeth

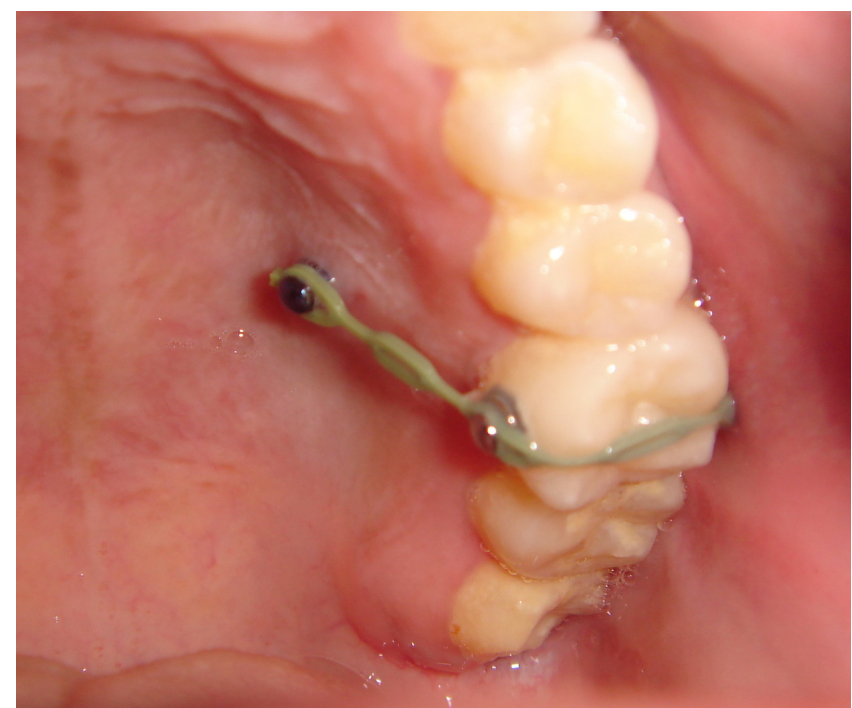

Fig. 2 - Microimplant used for intrusion of an over erupted molar

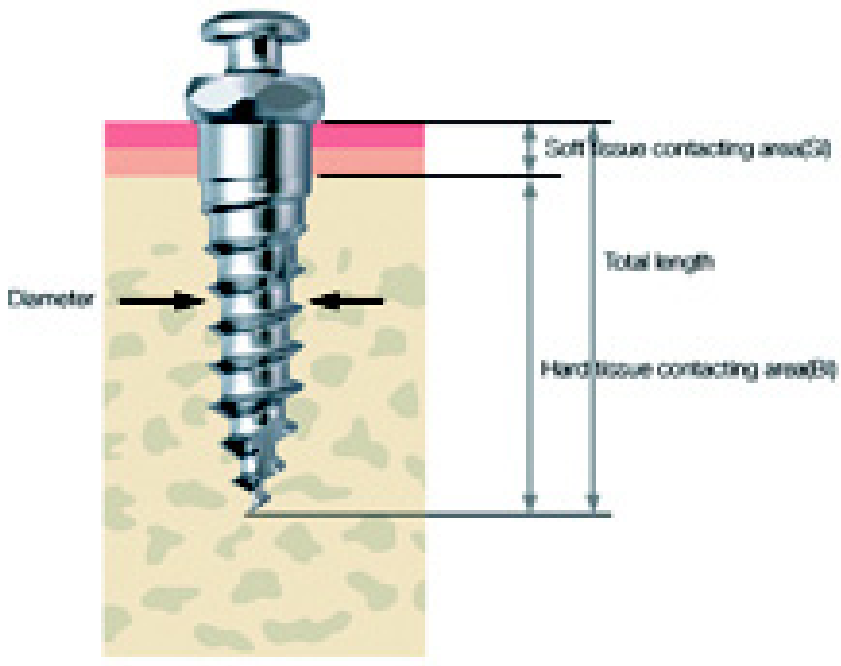

Fig. 3 - Contemporary self-drilling implant design

\section{Placement Technique}

Most orthodontists place their microimplants themselves as its relatively simple to place and requires only local anesthesia. Self tapping implant needs a predrilling using a pilot drill.

In self drilling method, implant itself acts as the drill as it is inserted in the bone.

After selection of site of insertion, topical anesthesia is used to anesthetize the area.

Topical anesthesia (15\% Novocain) is preferred over injectable local anesthesia as it anesthetizes only the overlying soft tissues without anesthetizing the roots of the teeth. This helps us during implant insertion as proximity to root can be gauged by pain reaction in patient.

Microimplants can be either hand driven or engine driven depending on operator preference. (Fig. 4, 5)

After placement of implants they can be immediately loaded with orthodontic force as osseointegration is not desired.

Removal of implants can be performed easily without anesthesia.
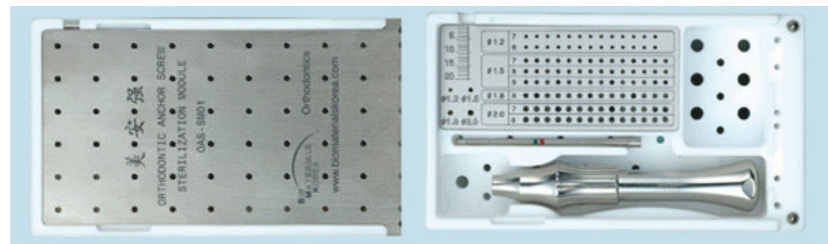

Fig. 4a - Microimplant insertion kit

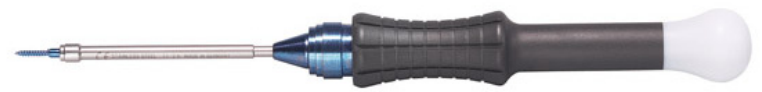

Fig. 4b - Microimplant insertion hand driver and insertion blade

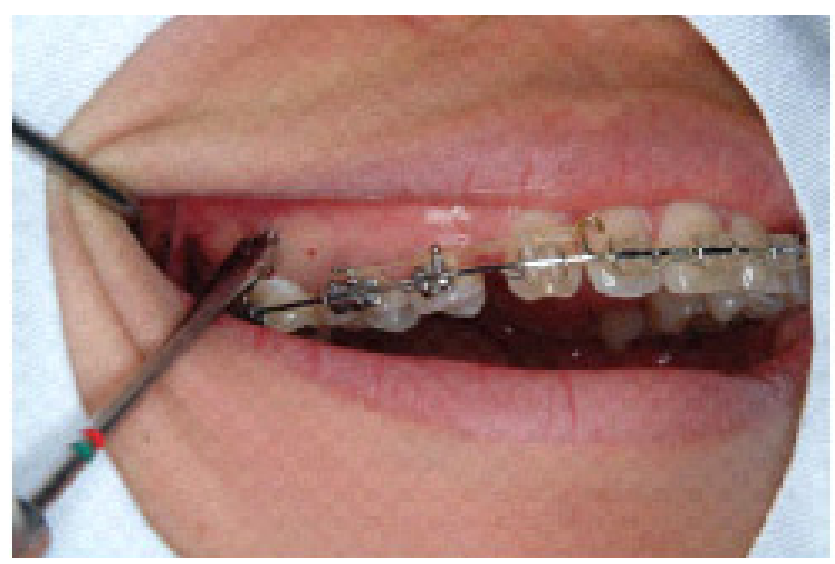

Fig. 5 - Microimplant insertion using hand driver

\section{Sites for Implant Placement}

The most common locations for placing of micro implants are buccal alveolar bone in maxilla and mandible, palate and retro molar pad area.

Their success percentage today ranges from 70-90\%. 


\section{Complications and Failures}

Because of ease of use and widespread applications usage of microimplants is increasing exponentially and it is going to be more and more popular in time to come.

But with widespread usage there is always risk of potential misuse or complications.

Potential complications of microimplants include ${ }^{5}$

" Mobility of Microimplants (Fig. 6)

" Oro-Antral communication

" Peri-implantitis

" Proximity to tooth-root (Fig. 7)

" Undesirable tooth movement

" Microimplant fracture

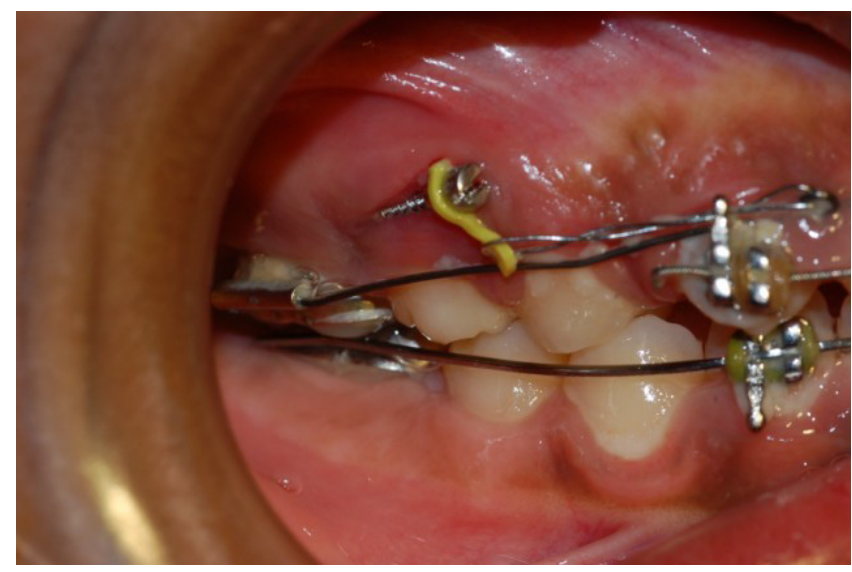

Fig. 6 - Microimplant failure due to loosening

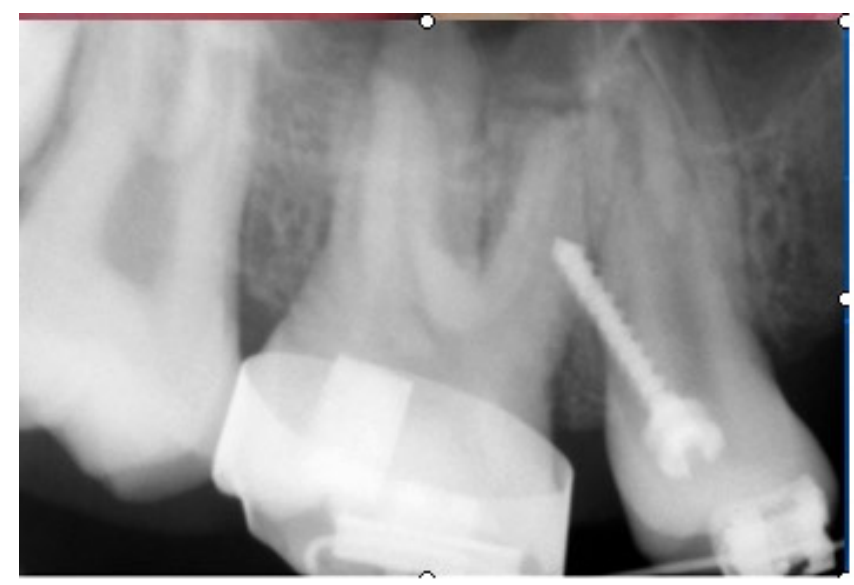

Fig. 7- Root contact of Microimplant

\section{Case report}

A 48yr old female patient reported with missing lower right second premolar, lower right first molar and lower left first molar $(35,36,46)$. She had supraerupted upper left and right upper first $\operatorname{molars}(16,26)$. (Fig. 8, 9)

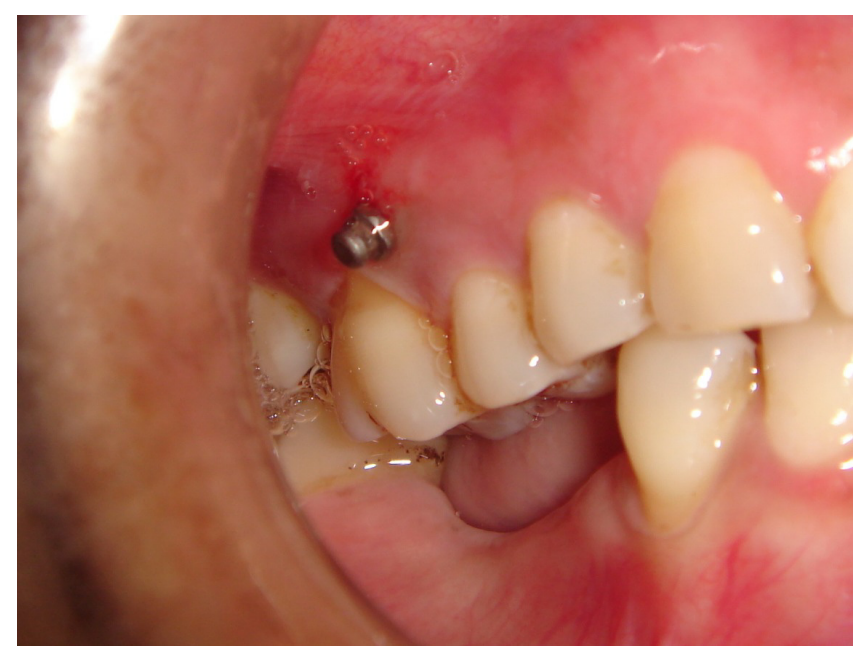

Fig. 8 - Right Buccal View (Pretreatment)

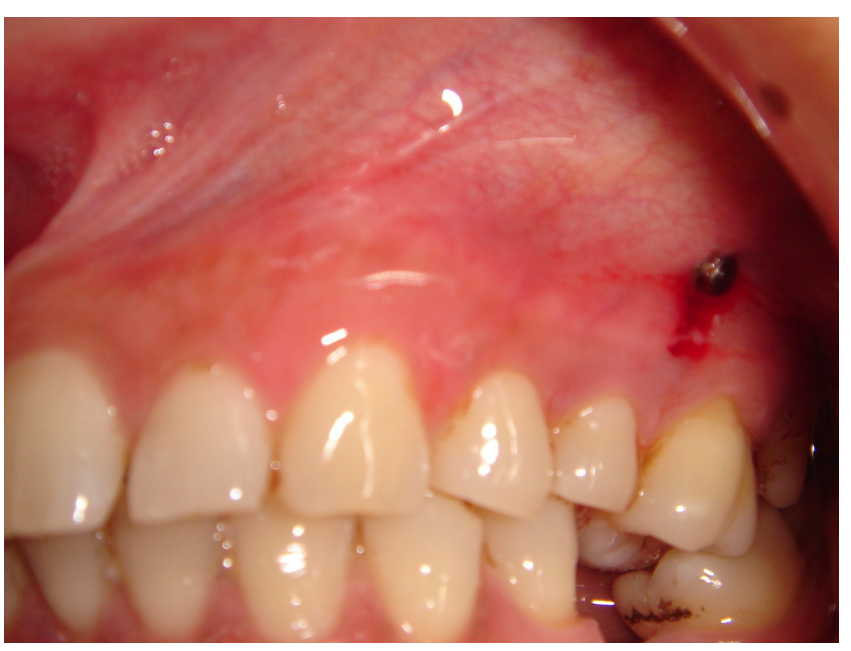

Fig. 9 - Left Buccal View (Pretreatment)

She desired replacement of missing teeth using fixed bridges. On examination it was observed that the supraerupted teeth had reduced the space available for prosthodontic replacement of missing teeth in vertical dimension. Treatment was planned to intrude the supraerupted upper right and left first molars using orthodontic microimplants.

One microimplant was inserted buccally and one palatally to each supraerupted tooth.

The microimplants were placed on buccal aspect between roots of 15, 16 and 25, 26 (Fig. 8, 9). Palatally the microimplants were placed between 16, 17 and 26, 27 (Fig. 10). This was done to allow the force to pass diagonally as close to centre of resistance preventing tipping of the teeth.

Bondable attachments (brackets or buttons) were placed on buccal and palatal surfaces of 16 and 26 to allow attachment of elastic chain to the teeth. The elastic chain was attached from head of microimplant to the bondable attachments on the teeth. 


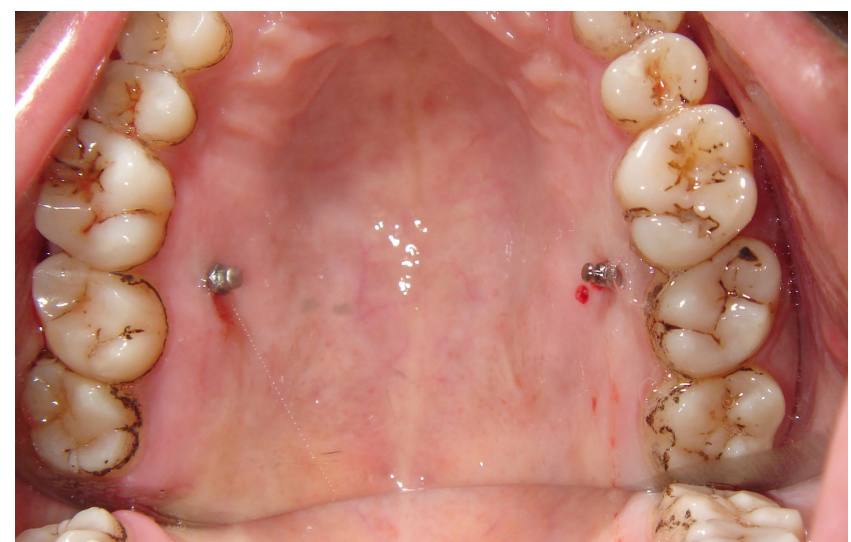

Fig. 10 - Occlusal View of Inserted Palatal Microimplants

The supraerupted teeth were intruded approximately $3 \mathrm{~mm}$ each in three months which leveled the occlusal plane. Crown preparations were performed on lower posterior teeth to receive porcelain fused to metal bridges replacing missing teeth.

Microimplants were removed once the final crowns were cemented. (Fig. 11)

The intrusion achieved is stable as the intruded teeth are in occlusion with lower crowns which will prevent their supraeruption. The entire procedure lasted around 4 months and patient received a healthy, functional and beautiful smile without compromising sound tooth structure.

\section{Discussion}

Microimplants are being used by orthodontists in cases of malocclusion which require high anchorage. They offer stationery anchorage which can be used for intrusion, retraction or uprighting of the teeth. They provide innumerable possibilities for bringing about desired tooth movement without taxing anchor teeth. Intrusion of teeth orthodontically without usage of microimplants is a very difficult tooth movement to bring about due to its reactive effect of extrusion on anchor teeth.

Microimplants are indicated ${ }^{6}$ in orthodontics for,

1) Intrusion of tooth or group of teeth

2) High anchorage cases requiring maximum retraction of anterior teeth

3) Protraction of molars

4) Uprighting of tilted molars

5) Forced eruption of impacted third molars

6) Periodontally compromised cases

They can be placed successfully in maxillary and mandibular buccal alveolar area, retromolar area, palate and anterior maxillary and mandibular region.

The procedure used for placement of microimplants is very simple, non invasive and can be performed
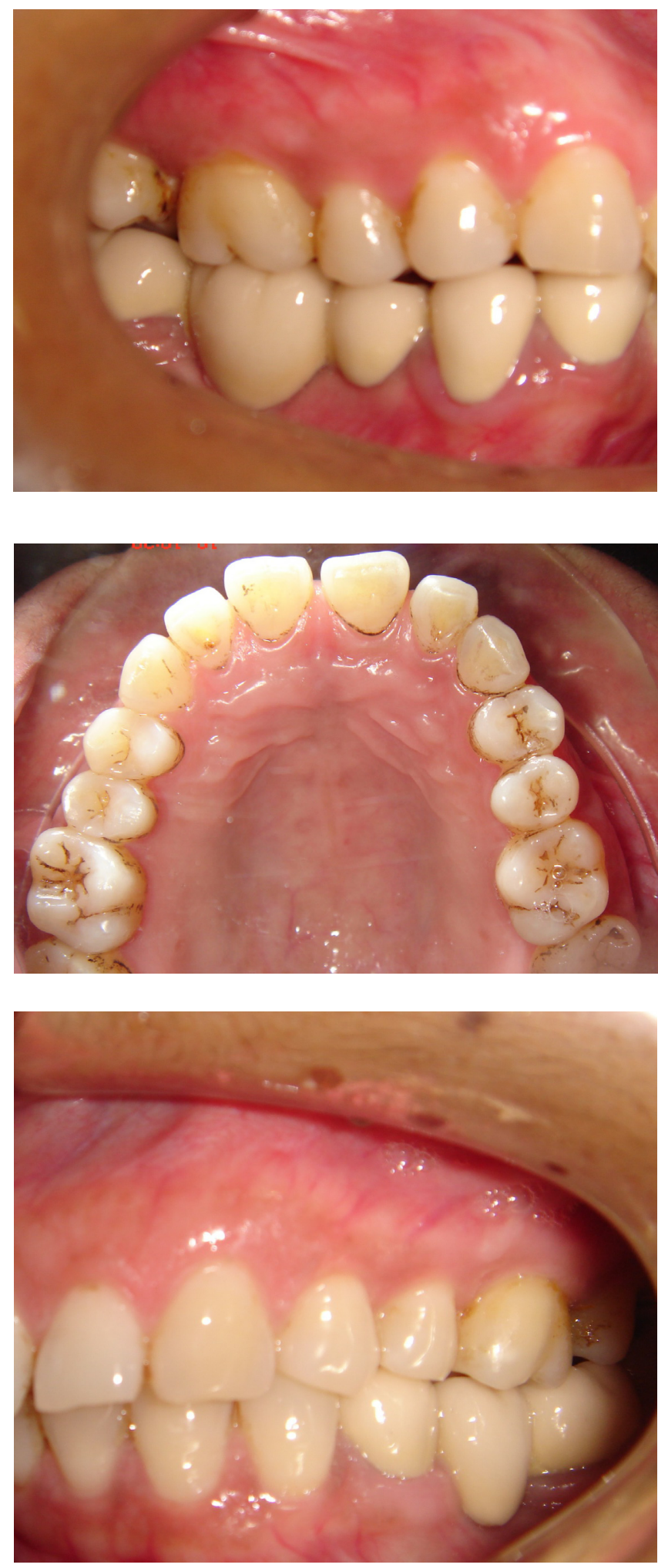

Fig. 11a, b, c - Post Treatment Right and left Buccal and Occlusal Views with Crowns Cemented

under local or topical anesthesia. Care should be taken to place them in between roots to prevent root damage. Also placing microimplants in close proximity to important anatomical landmarks should be avoided. 
Post treatment, they can be removed easily using manual hand drill with or without local anesthesia.

\section{Conclusion}

Absolute anchorage has been an orthodontist's dream and microimplants have become one of the most effective tools for achieving it.

This new approach has brought about a paradigm shift in orthodontic treatment planning.

Microimplants can also be used in various clinical situations like mesially tipped teeth adjacent to missing teeth, fractured teeth, periodontally compromised teeth etc to facilitate their restoration. ${ }^{7}$

Restorative dentists, periodontists and surgeons should ensure that they have a clear understanding of the many applications of orthodontic microimplants when presenting patients with options for correcting occlusal problems.

The results achieved in cases of intrusion using microimplants are stable and entire procedure is simple and conservative ${ }^{8}$.

\section{References}

1) Gainsforth BL, Higley LB. A study of orthodontic anchorage possibility in basal bone Am J Orthod Oral Surg 1945;1:406-17

2) Linkow LI, Weiss JL. The endosseous blade. A progress report. Int J Orthod. 1969 Dec;7(4):155-65

3) Roberts WE, Smith RK, Zilberman Y, Mozsary PG, Smith RS. Osseous adaptation to continuous loading of rigid endosseous implants Am J Ortho 1984;86:95-111

4) Kanomi R. Mini-implant for orthodontic anchorage J Clin Orthod. 1997 Nov; 31(11):763-7.

5) Hoste S, Vercruyssen M, Quirynen M, Willems G. Risk factors and indications of orthodontic temporary anchorage devices: a literature review.Aust Orthod J. 2008 Nov; 24(2):140-8. Review.

6) Sohn DS, Lee JK, An KM. Minor tooth movements using microimplant anchorage: case reports. Implant Dent. 2008 Mar; 17(1):32-9.

7) Mizrahi E, Mizrahi B. Mini-screw implants (temporary anchorage devices): orthodontic and pre-prosthetic applications. J Orthod. 2007 Jun; 34(2):80-94.

8) Kravitz ND, Kusnoto B, Tsay TP, Hohlt WF. The use of temporary anchorage devices for molar intrusion. J Am Dent Assoc. 2007 Jan; 138(1):56-64. Review. 